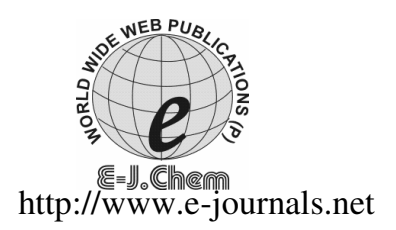

ISSN: 0973-4945; CODEN ECJHAO

E-Journal of Chemistry

2011, 8(4), 1504-1511

\title{
Practical Approach for the Determination of Response Factors of Impurities in Drugs by HPLC
}

\author{
DHARMENDRA KUSHWAH ${ }^{*}$, HARESH B. PATEL, \\ PRAVEEN K. SINHA and PIJUSH K. JANA \\ Unimark Remedies Ltd., 337, Kerala Nalsarover Road, Vill. Kerala, India \\ Tal. Bavla, Dist. Ahmedabad, Gujarat-382220, India \\ kushwahd@rediffmail.com
}

Received 31 August 2010; Revised 28 January 2011; Accepted 28 February 2011

\begin{abstract}
For the determination of accurate quantity of impurities in the samples authentic impurity standards or response factors at a given wavelength must be known. In the presented work a convenient method for determination of relative response factors of impurities has been described without using an authentic impurities standard. An approach for the determination of response factors of the impurities where impurity standard is physically not available was developed and verified using different approaches. One such method was developed and verified by RP-HPLC using Cosmosil C18 MS-II column at UV $238 \mathrm{~nm}$. Two different approaches were employed and the verification of correctness of approach was done using a known related substance of known response factor.
\end{abstract}

Keywords: Response factor (RF), RP-HPLC, Montelukast sodium (MNT), Michaels adduct.

\section{Introduction}

Impurities arising from the manufacturing process or via degradation are required to control in the drug substances and drug product. There are guidelines from the international conference on harmonization $^{1-2}$ (ICH) for reporting threshold, identification threshold and quantification threshold of impurities in new drug substances and drug products. It is very important to determine the actual reproducible values of impurities within these threshold values. The most accurate method of quantifying the impurity is to use external standard of the impurity, this is not always practically possible due to the non availability of ample supply of impurities. It is very difficult to isolate or synthesize and to maintain the impurities standard over several years as this also requires periodic reevaluation of impurities. 
Alternatively, response factors (RF) of the impurities are used for the determination of actual amount of impurities present in pharmaceuticals. The response factor is the ratio between a signal produced by impurity and active pharmaceutical ingredient (API) under the same detection condition. Response Factors (RF) are determined by the analysis of standards and are used to calculate the concentrations of analytes in samples using the following equation;

$$
\mathrm{RF}=\frac{\text { Response of Impurity }}{\text { Response of API }}
$$

No significant work has been done on the determination of response factors of impurities in drug product and drug substances using HPLC and UV-Vis. Detector. Ping Sun $e t$ al. ${ }^{3}$ has reported the determination of Relative Responses factor (RRF) of impurities in Paclitaxel in authentic pure materials which was estimated using high performance liquid chromatography equipped with ultraviolet and charged aerosol detectors ${ }^{3}$. Gregory et al. ${ }^{4}$ has reported the determination of relative Responses factor (RRF) using NMR spectrophotometer in absence of any authentic standards ${ }^{4}$. Liang et $a .^{5}$ used chemiluminescent nitrogen detection in pharmaceutical analysis for the determination of equimolar response for nitrogen present in impurities $^{5}$. A formula for the determination of relative response factors was derived for butter oil fatty acids and a regression line representing the best fit of the equation was calculated by Steen et al. ${ }^{6}$ using gas chromatography ${ }^{6}$.

$$
\mathrm{F}=a+b /(\mathrm{CN}-c)
$$

Where, $\mathrm{F}$ and $\mathrm{CN}$ are the relative response factor and the number of carbon atoms in the fatty acid butyl esters, respectively and a and $b$ are constants. Nussbaum et l. $^{7}$ used chemiluminescence nitrogen-specific detector for the determination of relative UV response factors by HPLC for nifedipine. Influence of relative response factor in the determination of organic micro contaminants with isotopically labeled standards was studied by Luigi et al. ${ }^{8}$ in the in the analysis of organic micro contaminant entails. Investigation of response factor ruggedness for the determination of drug impurities using high-performance liquid chromatography with ultraviolet detection was done by Bernard A. Olsen et al ${ }^{9}$.

In the presented work two different approaches have been demonstrated for the determination of response factors of unknown and unspecified impurities and the verification is done using authentic impurity standard.

\section{Experimental}

Acetonitrile and methanol of HPLC grade were used of Rankem. Ultra pure millipore water was used. Ammonium bicarbonate (AR grade) triethylamine (HPLC grade), trifluoroacetic acid (LR grade) were obtained from Merck, In house prepared montelukast working standard, sample and michael adduct impurity wee used.

\section{Instrumentation and chromatographic conditions}

The HPLC system (alliance, waters) consisting of UV / PDA detector empower software was used. Analytical balance (Mettler Toledo) was used. HPLC analysis was conducted using a Cosmosil MS-II, $250 \mathrm{~mm} \times 4.6 \mathrm{~mm}, 5 \mu \mathrm{m}$ particle size column. Mobile phase A constituted of $0.01 \mathrm{M}$ ammonium bicarbonate solution, added tritely amine $2 \mathrm{~mL}$ per litter and $\mathrm{pH}$ adjusted to 7.3 with trifluoroaceic acid, buffer and $60 \%$ and acetonitrile $40 \%$. Methanol was used as mobile phase B and diluent. Program gradient elution (time/min.) $\% \mathrm{~B}-0 / 13,45 / 87,50 / 87,53 / 13,60 / 13$ was used with UV detection at $238 \mathrm{~nm}$, flow rate $2 \mathrm{~mL} / \mathrm{min}$, column oven temperature $40^{\circ} \mathrm{C}$ and injection volume $10 \mu \mathrm{L}$. 


\section{Results and Discussion}

The IUPAC name of montelukast sodium compound with structure A is [1-[[[(1R)-1-[3[(E)-2-(7-chloroquinolin-2yl)ethenyl]phenyl]-3-[2-(2-hydroxypropan-2-yl)phenyl] propyl] sulfanyl]methyl]cyclopropyl]acetate commercially available as sodium salt. (Molecular weight 608.17)
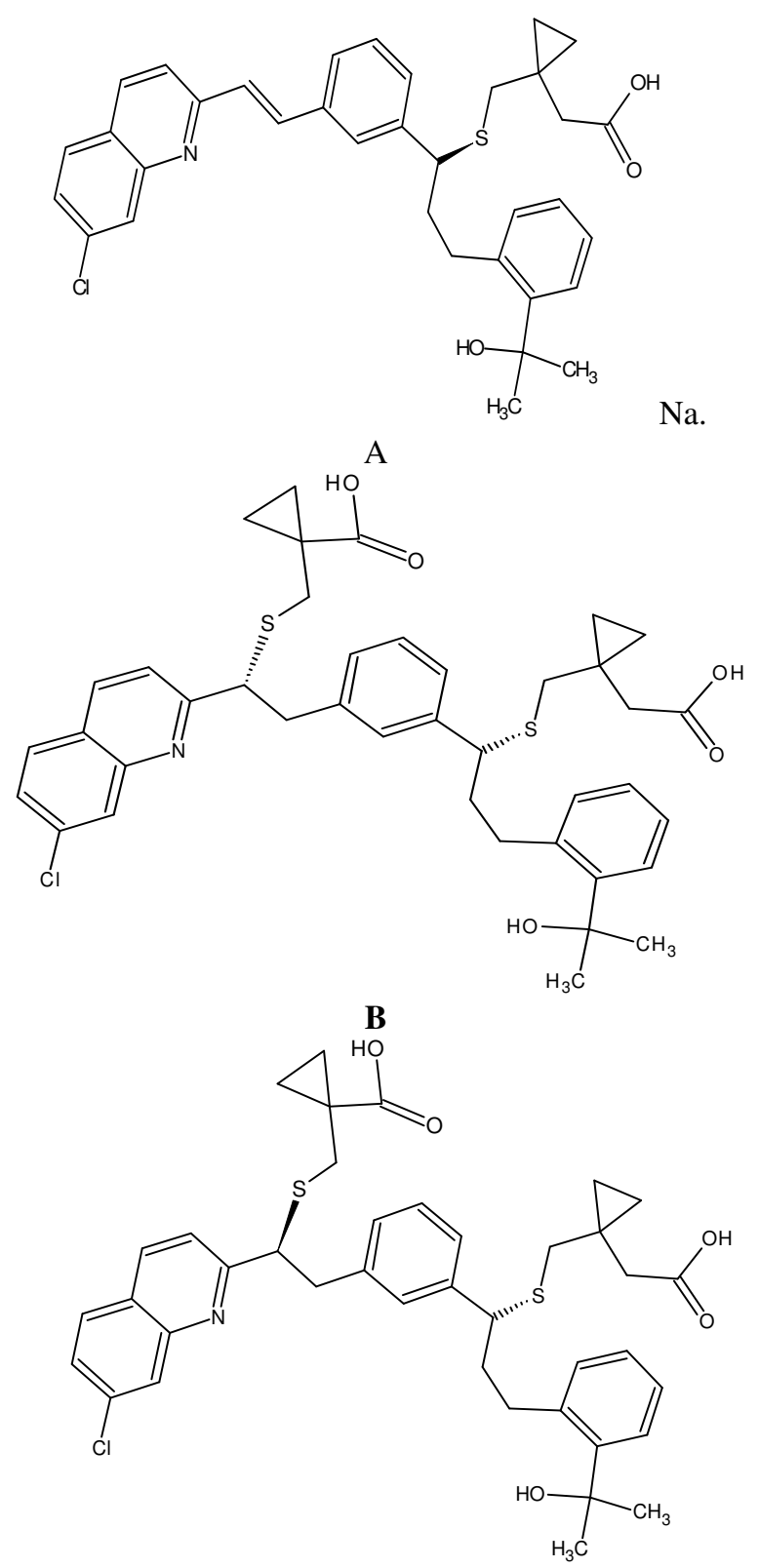

C

Figure 1. Structure of montelukast sodium compound (A); and impurity Micheal adduct-1(C) and adduct -2 (D). 
Compound with structure $\mathrm{B}$ and $\mathrm{C}$ are impurity micheal adduct present in two isomeric forms micheal adduct-1 and micheal adduct-2. IUPAC name of both the impurities are; 1-[[[(1R)-2-[3-[(1R)-1-[[[1-(carboxymethyl)cyclopropyl]methyl] sulfanyl]-3-[2-(2-hydroxy propan-2-yl)phenyl]propyl]phenyl]-1-(7-chloroquinolin-2-yl)ethyl] sulfanyl] methyl] cyclopropanecarboxylic acid and 1-[[[(1S)-2-[3-[(1R)-1-[[[1 (carboxymethyl) cyclopropyl]methyl] sulfanyl]-3-[2-(2-hydroxypropan-2-yl)phenyl] propyl] phenyl]-1-(7-chloroquinolin-2-yl)ethyl] sulfanyl] methyl] cyclopropane carboxylic acid. (Molecular weight 717.23)

Chromophoric structure of both the compounds is almost similar hence the molar absorption coefficient of both the components will be almost the same at $238 \mathrm{~nm}$. The UV spectra of micheal adduct-1, micheal adduct- 2 and montelukast are shown in Figure 2.

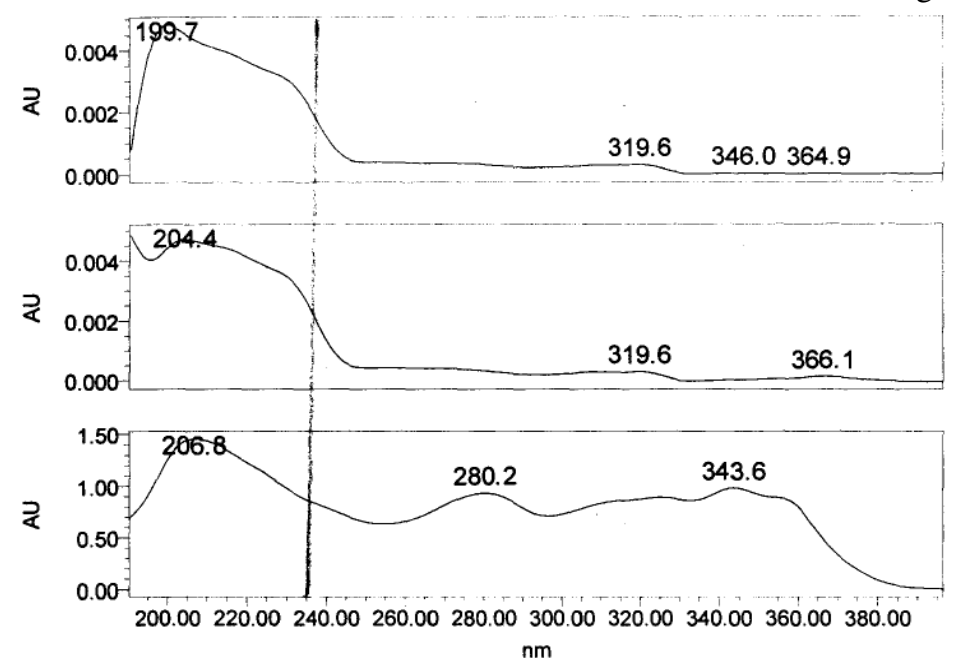

Figure 2. UV spectra of micheal adduct-1, 2 and montelukast

The response factors were determined by two different approaches. In approach-1 two types of samples, sample A and sample B of montelukast sodium were selected. Sample A contains very trace amount of michael adduct impurity and it was prepared by subsequent purification and re-crystallization and sample B contains some higher amount of michael adduct impurity. Sample A and sample B were blended in different compositions and then individual sample A, sample B and different blended mixtures were injected separately. Concentration of the main drug was adjusted in such a way that, it is within the acceptable linearity range of HPLC. The area count and \% Area for both micheal adducts were taken by adding the response of both the peaks of micheal adduct-1, micheal adduct-2 added. Theoretical $\%$ area was calculated as per formula given below;

Theoretical \% area $=\left\{\left(\mathrm{A}_{1} \times \mathrm{R}_{1}\right)+\left(\mathrm{A}_{2} \times \mathrm{R}_{2}\right)\right\} / 100$

Where, $A_{1}$ and $A_{2}$ are the area of impurity in sample $A$ and sample $B$ and $R_{1}$ and $R_{2}$ are concentration of sample A and sample B respectively in the blended samples. (\% area in B $\mathrm{x}$ ratio added) $\} / 100 \mathrm{RF}$ values are calculated as per formula given below;

$$
\mathrm{RF} \text { value }=\text { Theoretical } \% \text { area } / \text { Actual } \% \text { area }
$$

RF value was calculated for individual blended mixture and finally average RF value was calculated. The average calculated, RF value obtained is 1.06 (Table 1). Representative chromatograms are given in Figure 3 to Figure 5. Concentration of main drug was adjusted such, that it is within the acceptable linearity range of instrument (HPLC). 
Table 1. Determination of RF value of unknown impurity (Approach-1)

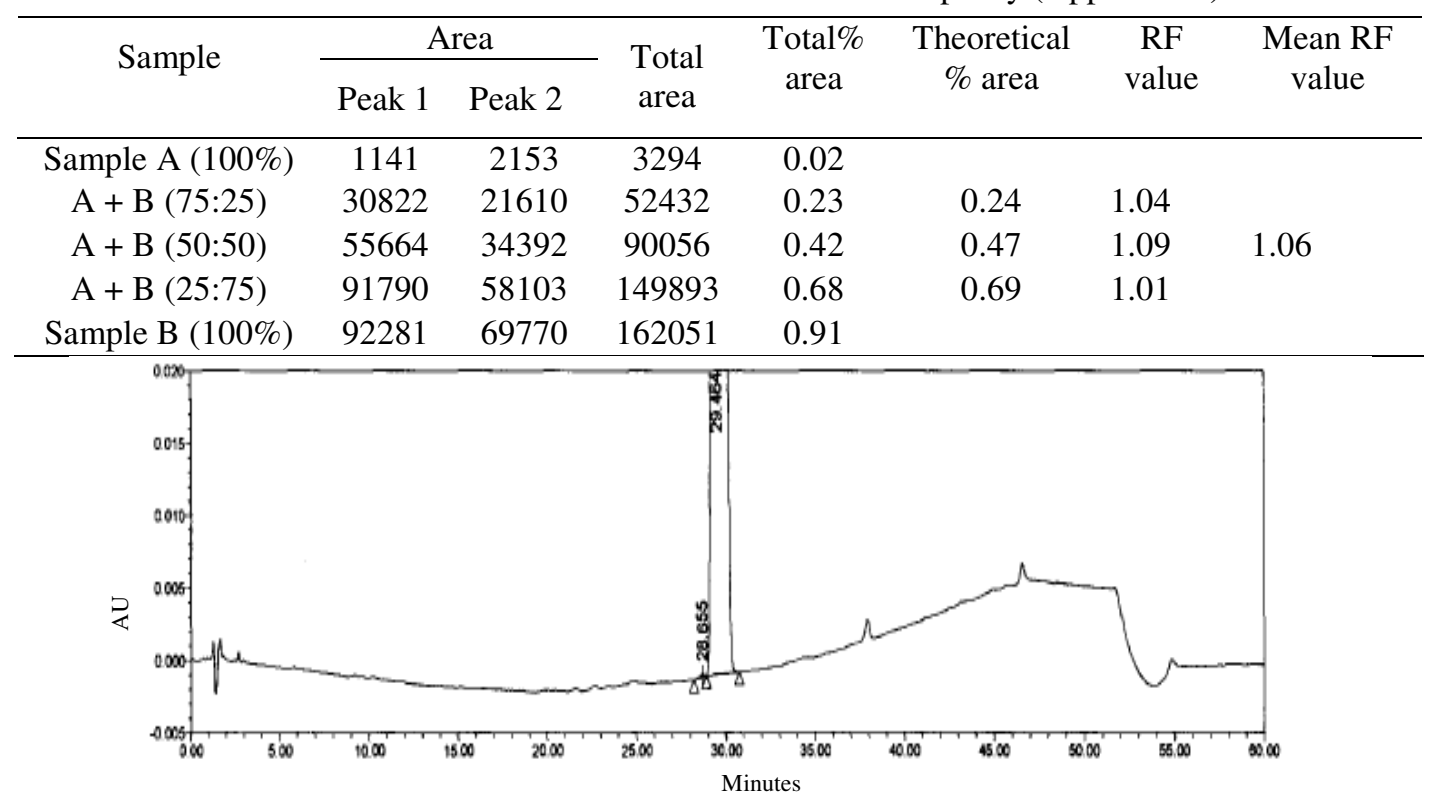

Figure 3. Chromatogram of sample A

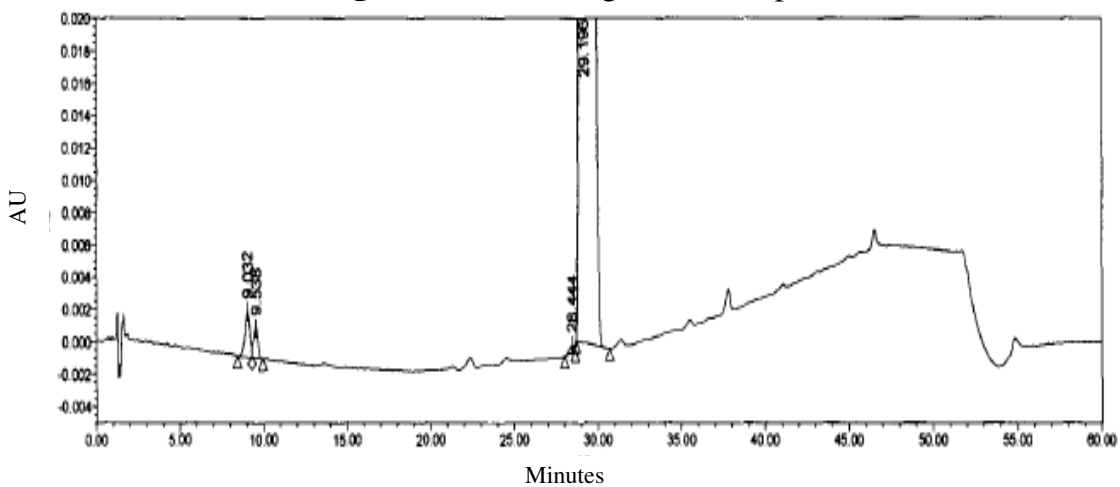

Figure 4. Chromatogram of mixture of sample A and B (50:50)

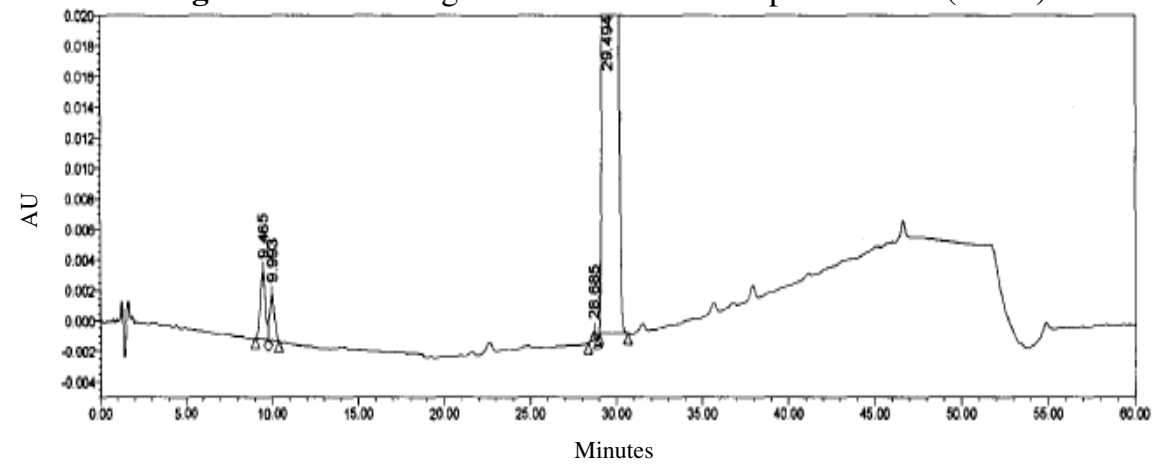

Figure 5. Chromatogram of sample B 
In approach-2 linearity was plotted with the total area of micheal adduct $(1+2)$ against the micheal adduct concentration in all five samples. Concentration of michael adduct was calculated by multiplying \% area with RF value calculated as per Table 1 . Separately linearity of montelukast standard was determined at lower level (concentration similar to the concentration of micheal adduct $(1+2)$. The montelukast standard solutions were prepared similar to the concentration of michael adduct. RF value of micheal adduct $(1+2)$ was calculated using the slop method, as given below;

RF value $=$ slope of standard $/$ slope of impurity

RF value obtained with approach-2 is 1.05 (Table 2), which is very close to the value obtained with approach-1 (Table 1).

Table 2. Determination of RF value of unknown impurity (Approach-1)

\begin{tabular}{cccccc}
\hline & \multicolumn{3}{c}{ Impurity } & \multicolumn{3}{c}{ Montelukast standard } \\
Sample & Total area & $\%$ Area & Conc., $\mu \mathrm{g} / \mathrm{mL}$ & Area & Conc., $\mu \mathrm{g} / \mathrm{mL}$ \\
\hline Sample A (100\%) & 3294 & 0.02 & 0.424 & 9586 & 1.011 \\
A + B (75:25) & 52432 & 0.24 & 4.835 & 9401 & 2.022 \\
A + B (50:50) & 90056 & 0.43 & 9.918 & 43442 & 5.056 \\
A + B (25:75) & 149893 & 0.70 & 14.00 & 99154 & 10.112 \\
Sample B (100\%) & 162051 & 0.91 & 19.224 & 150559 & 15.168 \\
& & & & 200244 & 20.224 \\
\hline Correlation & 0.99316 & & 0.99957 & \\
Intercept & 863 & & & & \\
Slope & 9572 & & & & \\
& & & & & \\
\hline
\end{tabular}

Verification for RF value using impurity standard

For the verification of RF values obtained with approach-1 and approach-2, small amount of impurity was isolated using preparative HPLC. Linearity of micheal adduct $(1+2)$ was performed with montelukast standard as per USP and ICH guidelines ${ }^{10,11}$ and RF value was calculated using slope method (eq.5). The RF value obtained is 1.08 (Table 3) which is very close and is within acceptable range with the RF values obtained with approach-1 and approach- 2 . Representative chromatograms and linearity plots are given in Figure 6 and Figure 7.

Table 3. Verification for RF value using impurity standard

\begin{tabular}{|c|c|c|c|c|c|}
\hline \multicolumn{2}{|c|}{ Impurity } & & & \multicolumn{2}{|c|}{ Montelukast standard } \\
\hline \multicolumn{2}{|c|}{ Area } & Total area & Conc., $\mu \mathrm{g} / \mathrm{mL}$ & Area & Conc., $\mu \mathrm{g} / \mathrm{mL}$ \\
\hline Peak-1 & Peak-2 & & & & \\
\hline 1539 & 1110 & 2649 & 0.388 & 1636 & 0.272 \\
\hline 3031 & 2063 & 5076 & 0.775 & 4024 & 0.544 \\
\hline 4451 & 5127 & 9578 & 1.550 & 7428 & 1.089 \\
\hline 12497 & 11568 & 24065 & 3.100 & 17751 & 2.178 \\
\hline 24344 & 24664 & 49008 & 6.201 & 34235 & 4.355 \\
\hline 49762 & 47560 & 97322 & 12.402 & 66401 & 8.711 \\
\hline \multirow[t]{5}{*}{97809} & 96232 & 194041 & 24.803 & 149772 & 17.422 \\
\hline & Correlation & 0.99991 & & 0.99852 & \\
\hline & Intercept & 0.1077 & & 0.2466 & \\
\hline & Slope & 7875.24 & & 8537.46 & \\
\hline & & RF value & 1.08 & & \\
\hline
\end{tabular}




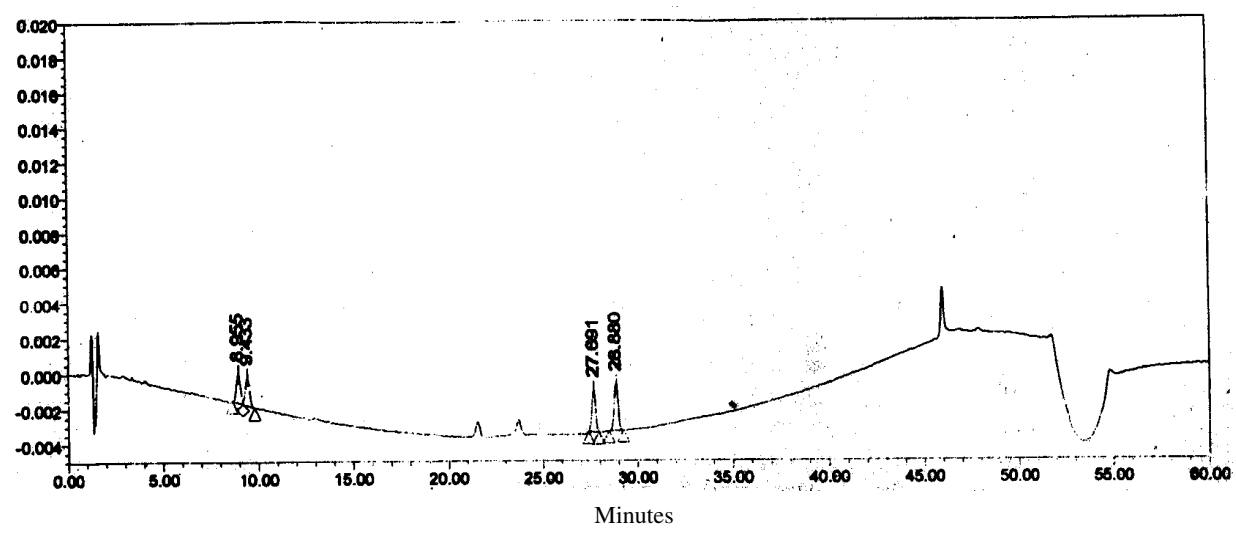

Figure 6. Chromatogram of Impurities with standard montelukast sodium

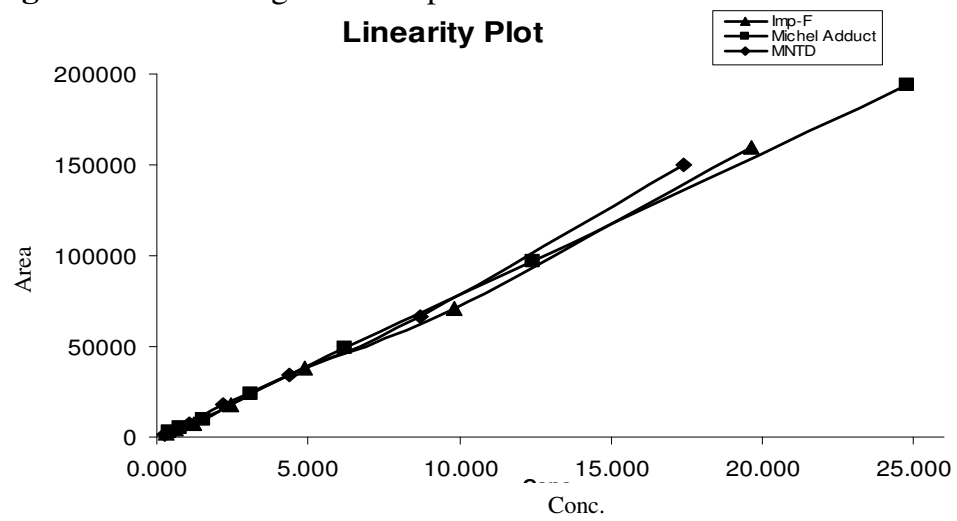

\section{Conclusion}

Figure 7. Linearity plot of impurities and standard

Determination of correct quantified value of any impurity is very important in pharmaceutical industry. The presented work describes two different approaches for the calculation of RF values without using impurity standard in drug substances and drug products. This method can be applied for any potential impurity present in sample. Verification of the approaches using impurity standard further strengthens the accuracy and correctness of the method.

\section{Acknowledgment}

Authors are highly thankful to the management of Unimark Remedies Ltd. for granting permission for the publication of this work.

\section{References}

1. ICH, Q3A (R2) Impurities in New Drug Substances: Text and Methodology, Current Step 4 version.

2. ICH, Q3B (R2) Impurities in New Drug Substances: Text and Methodology, Current Step 4 version.

3. Ping Sun, Xiande Wang, Lori Alquier_and Cynthia A. Maryanoff, J Chromatogr A, 2008, 1177(1), 87-91. 
4. Gregory K Webster Ian Marsden, Cynthia A Pommerening, Christina M Tyrakowski and Brian Tobias, J Pharm Biomed Anal., 2009, 49(5), 1261-1265.

5. Liang X, Patel H, Young J, Shah P and Raglione T, J Pharm Biomed Anal., 2008, 47(4-5), 723-730.

6. Steen S. Jacobsen, Claus C. Becker and Gunhild Hølmer, Chemometrics and Intelligent Laboratory Systems, 1994, 23, 231-234.

7. Nussbaum M A, Baertschi S W and Jansen P J, J Pharm Biomed Anal., 2002, 27(6), 983-993.

8. Luigi Turrio-Baldassarri, Alessandro di Domenico, Annarita Fulgenzi, Cinzia La Rocca, Nicola Iacovella, Fabrizio Rodriguez and Fabrizio Volpi, Microchimica Acta, 1996, 123(1), 45-53.

9. Bernard A. Olsen and Mark D. Argentine, J Chromatogr. A, 1997, 762(1-2), 227-233.

10. ICH, Q2 (R1) Validation of Analytical Procedures: Text and Methodology, Current Step 4 version.

11. United States Pharmacopeia, <1225> Validation of Compendial Procedures, USP32, NF-27, Volume $1,2^{\text {nd }}$ Supplement. 


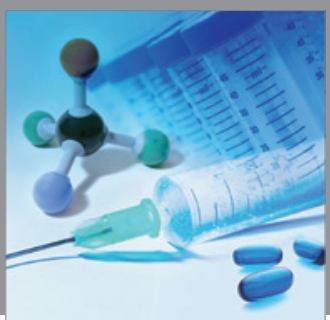

International Journal of

Medicinal Chemistry

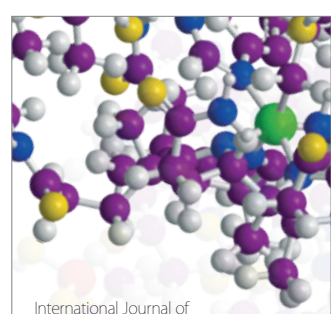

Carbohydrate Chemistry

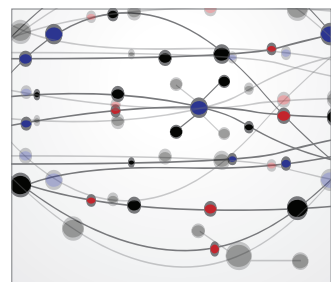

The Scientific World Journal
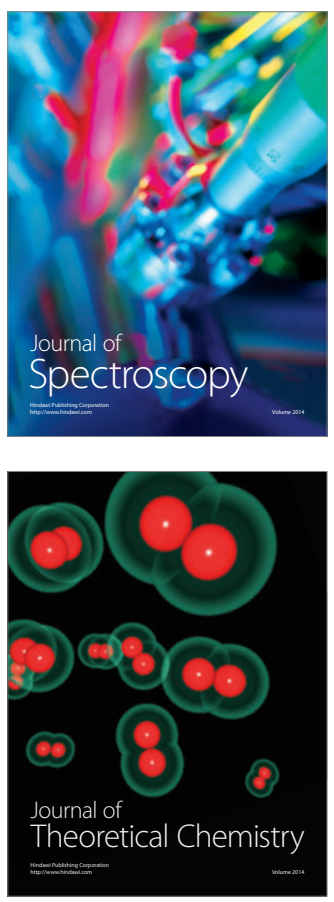
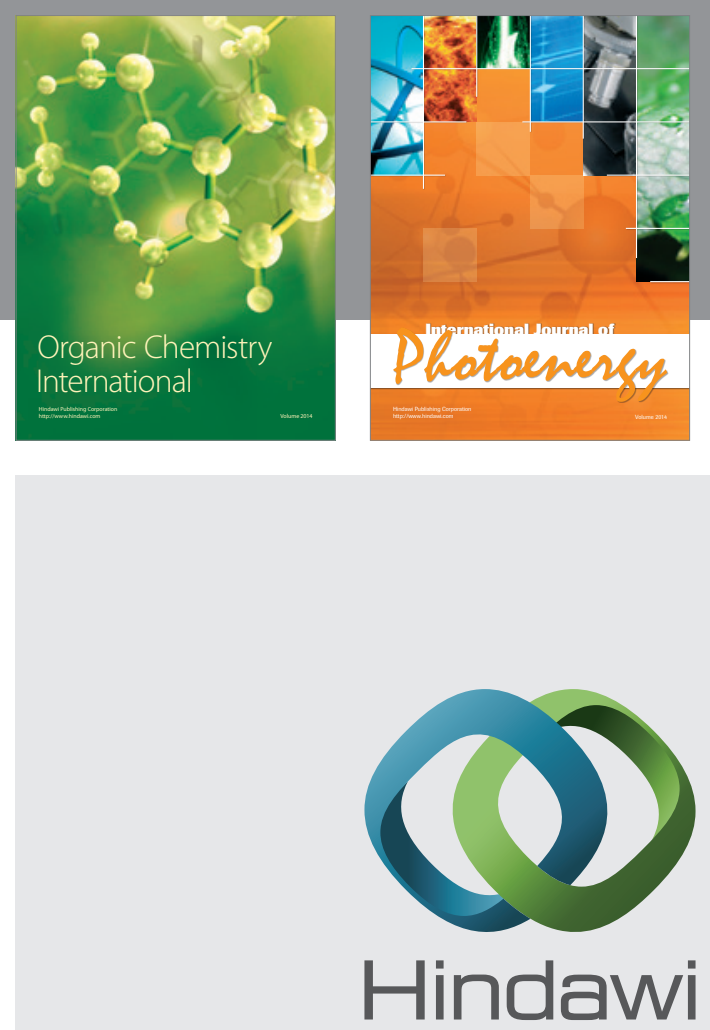

Submit your manuscripts at

http://www.hindawi.com
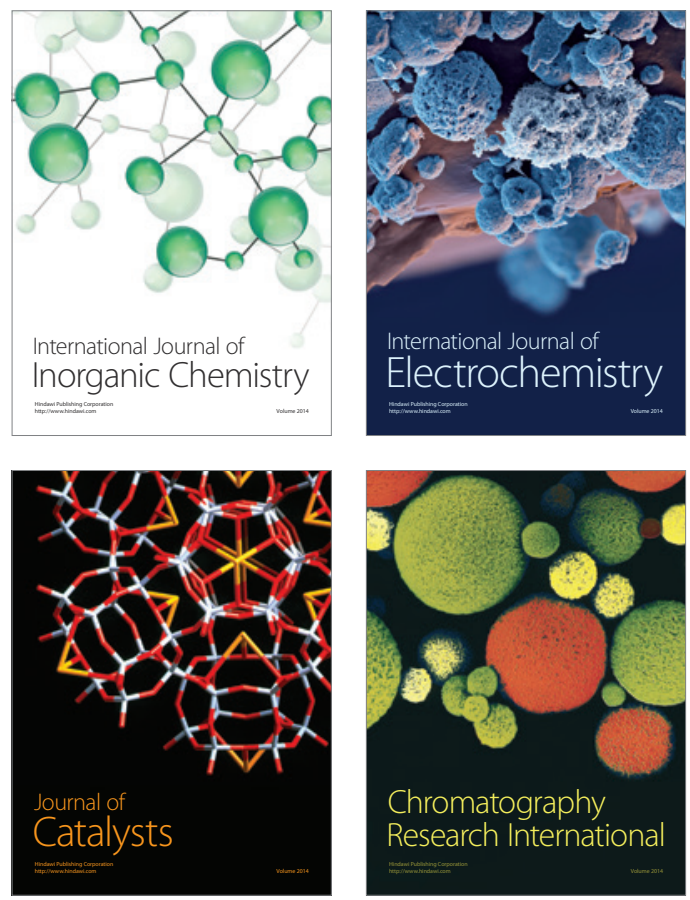
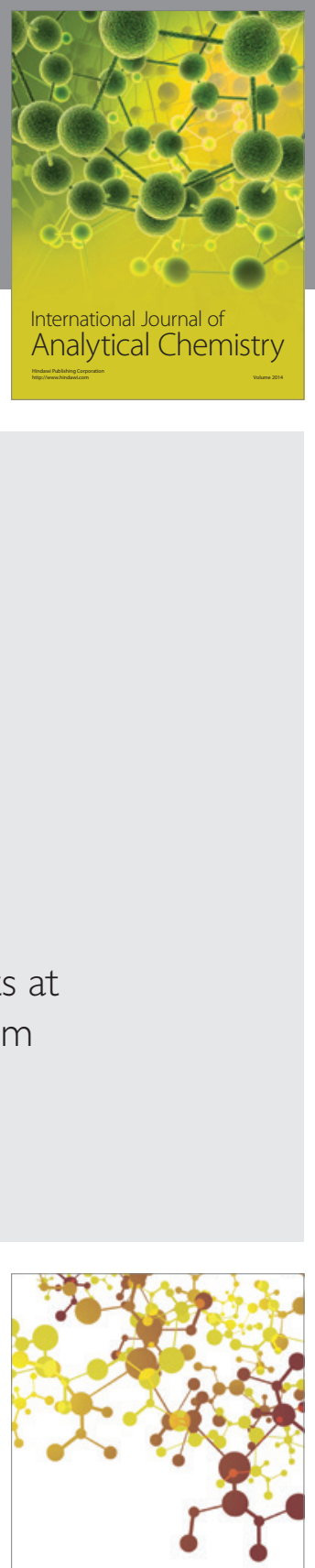

Journal of

Applied Chemistry
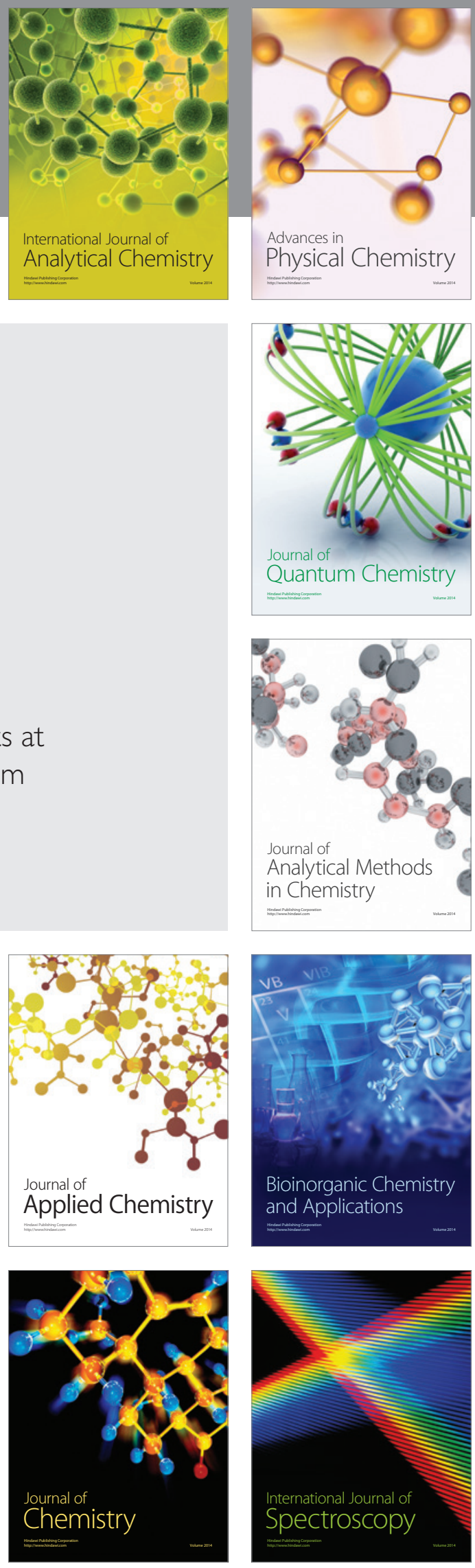